\title{
SOC-ASIC (State-of-Charge-Application Specific Integrated Circuit), A Battery Voltage Monitoring System for Series-Connected Battery Cells in Electric Vehicle for State-of-Charge Estimation

\author{
${ }^{* 1}$ Nakul K Pathak, ${ }^{2}$ Prasad R. Pande, ${ }^{3}$ Lokesh Heda, ${ }^{4}$ Parag Jawarkar \\ ${ }^{1-4}$ Department of Electronics Engineering, Shri Ramdeobaba College of Engineering \& Management, Nagpur \\ Email: pathaknk@rknec.edu,pandepr1@rknec.edu, hedalm1@rknec.edu, jawarkarps@rknec.edu
}

Received: 20th September 2018, Accepted: 11th October 2018, Published: 31st October 2018

\begin{abstract}
Increasing Green House Effect and reducing fuel storage of planet contributed highly due to automobile industry drives an alarming situation for researcher to look for alternative options for future generation vehicle. Tesla, Mahindra-eco and other automobile companies have already come up with concept of e-vehicle whose soul is battery and brain is Battery Management Unit. Our proposed design embodied SOC-ASIC (State-of-Charge-Application Specific Integrated Circuit) design for SOC (State-of-Charge) estimation of Series-connected Li-ion Battery cell used to build battery pack of hybrid or all- electric vehicles. It consists of high precision Array of dedicated instrumentation amplifier circuit which connects output voltage of terminal across each individual cell to ADC via array of switching network. Array of switching network consists of low power, low loss, and low threshold voltage switches driven by output of de-multiplexer circuit whose select lines controls from General Purpose Input-Output (GPIO) pins of microcontroller. Signal voltage after switching network process with Noise filter and Kalman filter to produce accurate and precise terminal voltage to ADC.
\end{abstract}

\section{Keywords}

Kalman Filter, Electric Vehicle (EV), State of Charge (SOC), Battery Monitoring.

\section{Introduction}

At the 16th Conference of the Parties held in 2010, Parties to the UNFCCC agreed that future global warming should be limited below $2^{\circ} \mathrm{C}$ relative to the pre-industrial temperature level [1] [2] [3].NASA's Goddard Institute for Space Studies (GISS), the average global temperature on Earth has increased by about $0.8^{\circ}$ Celsius ( $1.4^{\circ}$ Fahrenheit) since 1880 . Twothirds of the warming has occurred since 1975 , at a rate of roughly $0.15-0.20^{\circ} \mathrm{C}$ per decade. But why we should care about one degree of warming after all, the temperature fluctuates by many degrees every day where we live. A onedegree global change is significant because it takes a vast amount of heat to warm all the oceans, atmosphere, and land by that much. In the past, a one- to two-degree drop was all it took to plunge the Earth into the Little Ice Age [4].

Majorly the reason for Green House Effect is Green House Gases, which are water vapor, carbon dioxide, methane, nitrous oxide, and ozone, of which human activities have produced a $40 \%$ increase in the atmospheric concentration of carbon dioxide $\left(\mathrm{CO}_{2}\right)$, since the beginning of the Industrial Revolution (around 1750) from $280 \mathrm{ppm}$ in 1750 to $406 \mathrm{ppm}$ in early 2017 [5].

So to curb Green House Effect, world is moving towards smart and modern mode of transport. Electric Vehicle is one of such solutions which definitely help to cut down release of such heavy amount of carbon mono-oxide into the atmosphere due to vehicles based on internal combustion Engine. Government of India has also taken an initiative to towards incorporation of modern transport and set a target to rule out all internal combustion Engine base vehicles and run all electric vehicles on road by 2030 .

So, to help this target we must create a complete infrastructure for manufacturing and maintaining Electric vehicle to make it a big success which in turn helps our future generation. But this is not an easy task. There are many issues associated with Electric Vehicles (EV) like what should be the structure of vehicle, what types of motors to be used to run wheels as there is no fuel no internal combustion engine is required, how to increase running distance of EV without increasing battery stack which in turn put extra cost on user, what types of battery to be used, whether it will carry similar type of load as internal combustion engine based vehicle is carrying.

Out of which, battery is heart of the Electric Vehicle. There majorly two types of Electric Vehicles are presently available in market. One is Hybrid Electric Vehicle, which runs both on fuel and battery and another is All-Electric Vehicle, which has no internal combustion engine. As no fuel is being used, complete power is extracted from battery as it is the only source in All-Electric Vehicle. If we take the example of Tesla's All-Electric Vehicle which are introduced few years back, Battery stack is based on and developed using Li-Ion combination-based structure. Normally, vehicles use Lead-Acid battery to start their vehicle, to operate lights, indicators etc. But in case of All-Electric Vehicle, it is complete a different scenario as we are talking about extraction of power to run not only thing done by normal Internal combustion Engine based vehicle but to drive complete vehicle for longer distances. 
In a presented work, section 2 discusses the challenges faced during series connected voltage measurements of battery pack. Further it demonstrates the solution as a single ASIC development with detailed note about array of high precision instrumentation amplifier as one of the important block in ASIC design. An insight is given in further discussion about proposed high level blocks and its connections which in turn can be embedded as ASIC which has utility in between battery pack and controller. ASIC will also comprise of programmable switches which can be operated using microcontroller via demultiplexer. In section 3, discussion about expected outcomes is briefed also including impact on overall EV battery system improvement. Section 4 concludes the paper with proposed ASIC's enlighten future scope.

\section{Proposed Work}

It's always a challenge for researcher to boost charging speed of batteries used and increase operating distance of AllElectric Vehicle with a single charge. To aid this, we first should know State-of-Charge of batteries used in battery stack of battery module of All-Electric Vehicle. Development of a battery module capable of delivering 50KWh (say) of power using $5 \mathrm{~V}, 2000 \mathrm{mAh} \mathrm{Li}$-ion based battery cell to 3-phase Inductor motors used to drive your All-Electric Vehicle consists of multiple connections of Li-ion battery module either in Series or parallel connection.

Figure 1 illustrates proposed solution of problem consists of an embodiment of a dedicated Application Specific Integrated Circuit (ASIC) design for obtaining the State-of-Charge (SOC) by the voltage method of Series connected Li-ion battery cells used for building Battery packs of Battery module of Electric Vehicles (EVs). Available methods [14, 15, 16]are less capable of obtaining accurate state of voltage of battery cells as they fails in loading conditions and in case if any individual cell gets disconnected from circuit which fails to flow of current and circuit gradually unable to work.

In the considered invention, each battery cell is connected to a dedicated differential amplifier circuit, in this case instrumentation amplifier with overall gain 1, is used for accepting floating signal voltage given by individual battery cell. Here differential amplifier is used for converting floating signal voltage into un-floating signal voltage. Floating signal is given by each individual battery cell as difference voltage across the battery cell terminals. Now this floating signal needs to be converted into un-floating signal as this signal voltage will be fed to Analog-to-Digital Converter which accepts analog signals as single terminal signal. All signals from each individual differential amplifier can be obtaining by using single common ground.

Array of Dedicated Differential Amplifier Circuit solves another purpose of failing circuit in single-cell or multi-cells failure scenario. As the battery cells are provided with dedicated differential amplifier so failure in between cells does not affect the operation of complete circuit of obtaining terminal voltage. If any cell is damage from the circuit then the portion of cell connected to differential amplifier gets isolated from circuit and provides no voltage. The circuit also provides protection from short-circuit scenario. If any individual cell gets short-circuited still it does not affect the analysis of battery cell as each cell is virtually isolated with the help of dedicated differential amplifier.

Figure 2 depicts Differential amplifier used for embodiment is Instrumentation amplifier which converts floating input into single terminal signal. Also gain of Instrumentation amplifier is set as 1 . The gain of amplifier is purposefully kept at 1 to obtained unchanged terminal voltage from battery cell. Formula used for obtaining gain is

Where,

$$
\frac{\mathrm{V}_{\mathrm{o}}}{\mathrm{V}_{\mathrm{d}}}=\left(1+\frac{2 \mathrm{R}_{1}}{\mathrm{R}_{3}}\right)\left(\frac{\mathrm{R}_{7}}{\mathrm{R}_{4}}\right)
$$

Vo $\rightarrow$ output voltage from individual instrumentation amplifier

$\mathrm{Vd} \rightarrow$ differential voltage to individual instrumentation amplifier taken from battery terminals.

$\mathrm{R} 1, \mathrm{R} 3, \mathrm{R} 4, \mathrm{R} 7 \rightarrow$ resistances from individual instrumentation amplifier

For given circuit to work as differential amplifier, we have to consider $R_{4}=R_{6}, R_{7}=5, R_{1}=R_{2}$ and $R_{3}=R_{9}$.

Another reason for using Instrumentation amplifier in the circuit is to have high CMRR (Common Mode Rejection Ratio) which acts as excellent noise cancellation device if present at output terminal of battery cell.

Now the output of individual instrumentation amplifier array of differential amplifier circuit will be driven by an electronic switch in Array of Switching circuit. For testing purpose, we have used n-channel Metal Oxide semiconductor (n-MOS) as electronic switch to transfer the signal voltage which is terminal voltage form battery cell to filter for further processing. Each switch in now controlled via demultiplexer. Demultiplexer is been implanted to control multiple switches (n-MOS in this case) by using available General purpose Input-Output (GPIO) pins from microcontroller. These GPIO pins are limited so to control huge number of switches we need more dedicated pins to control which is practically impossible. So Demultiplexer solves this purpose.

Output of the switch will then be fed to noise filter and Kalman filter for further signal processing, noise cancellation and SOC estimation of Li-ion battery. Then the modified and accurate signal voltage of battery cell will be observed and stored as array in microcontroller and displayed if ask. 


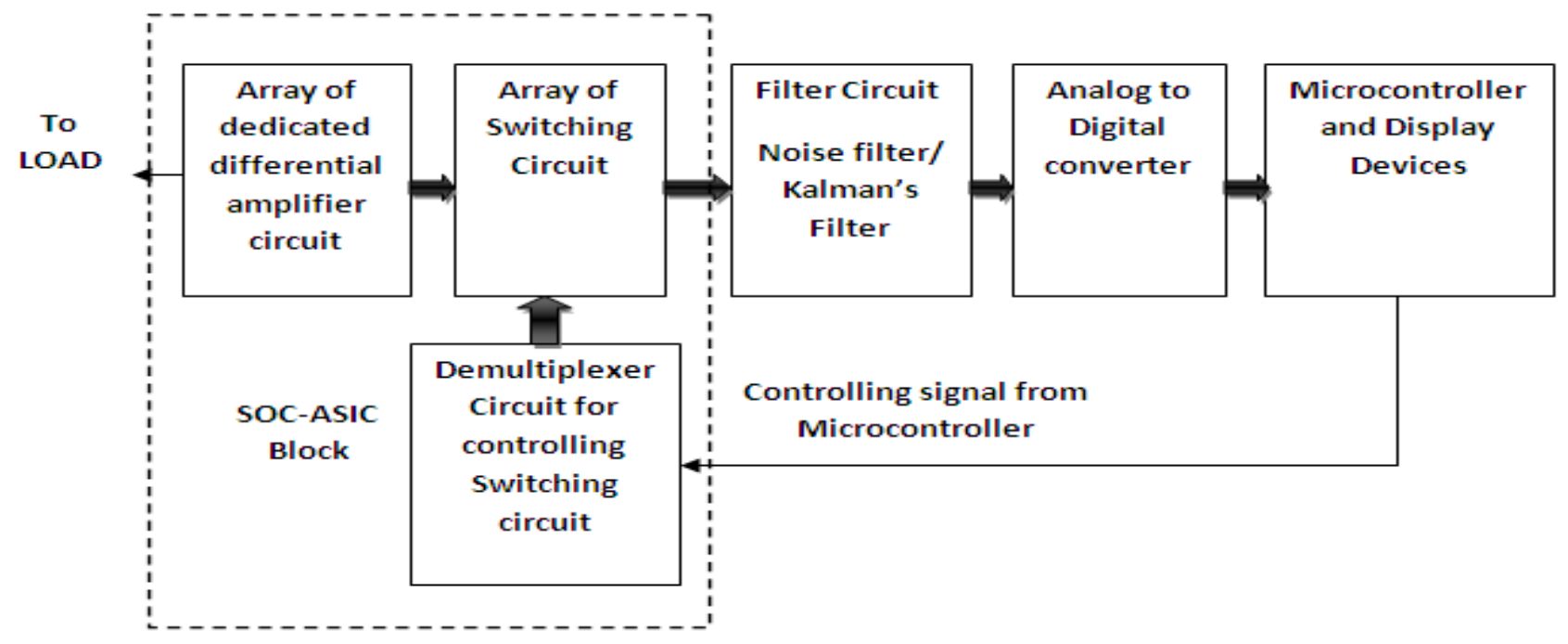

Figure 1: Proposed Block Diagram

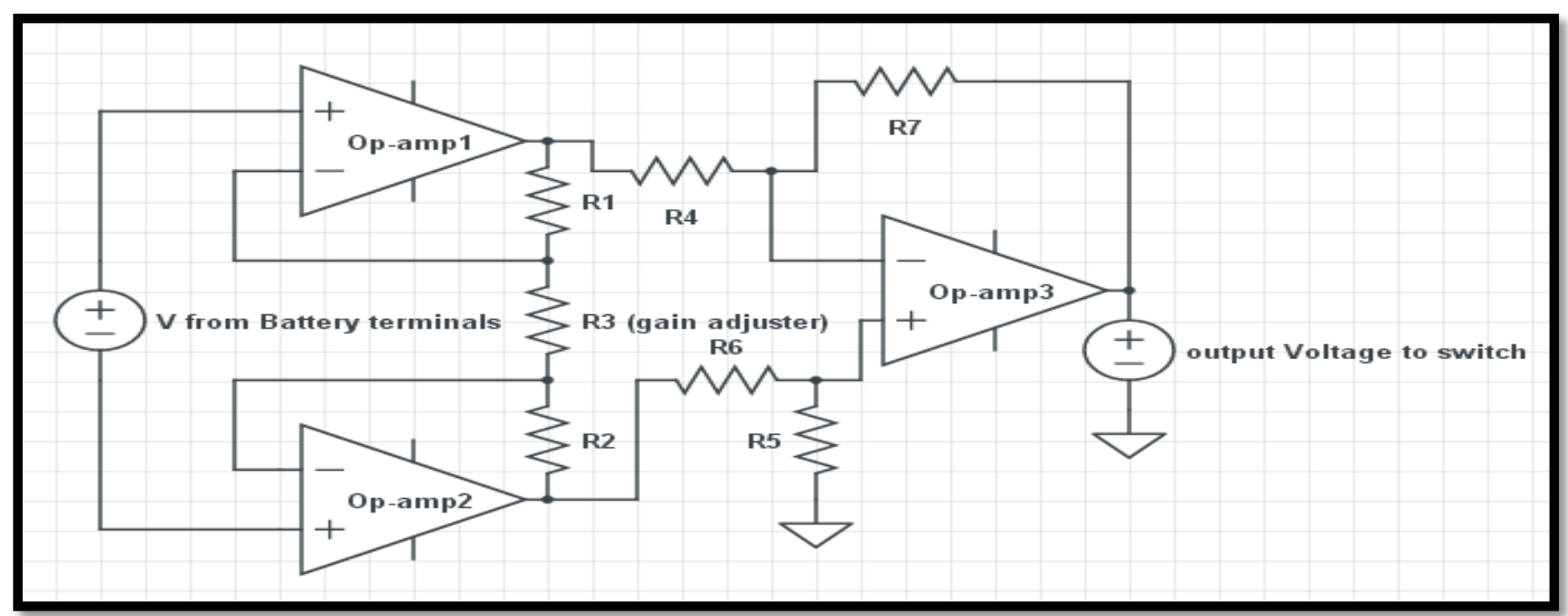

Figure 2: Dedicated Instrumentation Amplifier for Each Individual Battery Cell

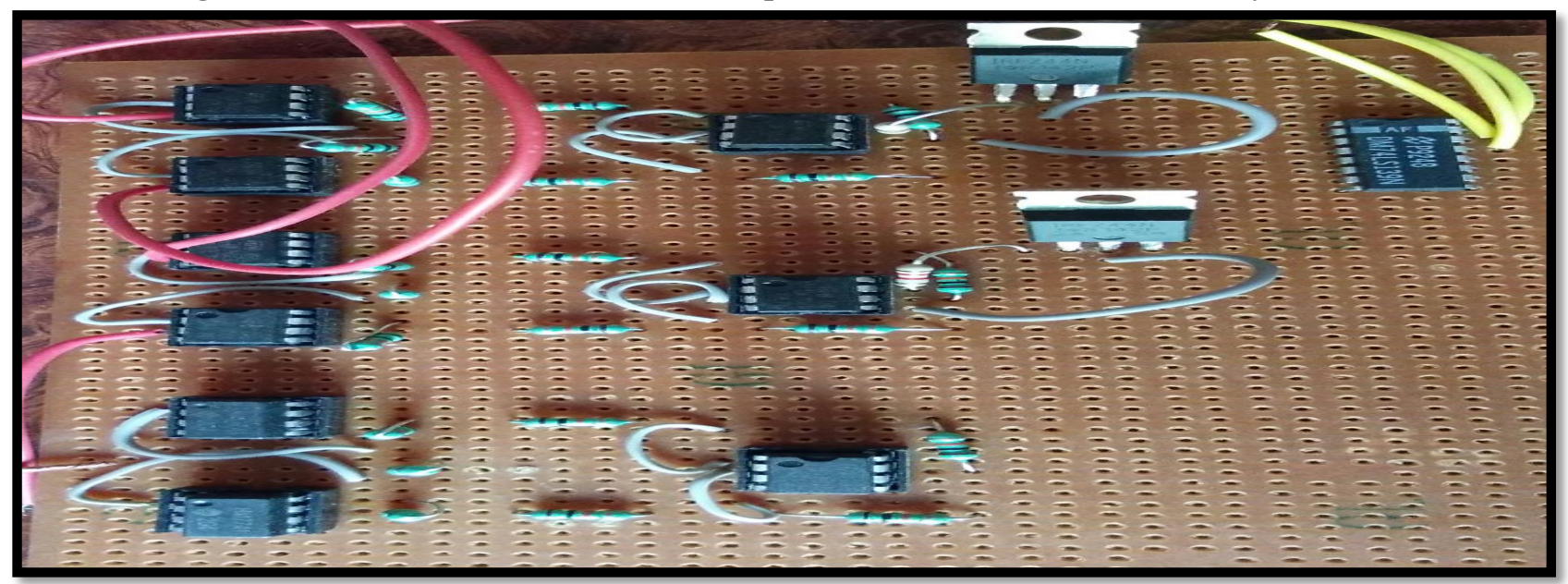

Figure 3: Implemented and Tested Circuit for 3 Series-Connected Li-ion Battery Cell 


\section{Results and Expected Outcomes}

In a series connected battery pack, under-voltage and overvoltage in run time situation will always become a problem. In addition to this, damaged cell or cell which needs replacement has to be isolated automatically without impacting performance of battery pack. A dedicated ASIC chip will help to integrate important blocks into one where programmable switches can control operations based on microcontroller decision through demultiplexer.

Figure 3 show actual discrete circuit implementation of dedicated Array of Instrumentation amplifier as differential amplifier circuit has been implanted helps in turn to obtain the voltage levels of 3 individual battery cell under short circuited and open circuited cases of voltage method of state of charge estimation. Individual cell does not affect the he estimation process. Embodiment of dedicated switching circuit inherently controlled via demultiplexer circuit enhances the capability to understand and analysis of each battery cell with the case considering availability of limited channel (ADC) Analog-to-Digital Converter.

Our system consists of circuit build as prototype to check the State-of-charge by calculating voltage of individual voltage of each battery cell of battery module of battery pack. Circuit is built using instrumentation amplifier with gain $\mathrm{A}_{\mathrm{IA}}=1$. Instrumentation amplifier is being used for each individual battery cell to measure difference voltage of battery cell across its terminals. Instrumentation amplifier is acting as difference amplifier for each battery cell, taking voltage appearing across terminals of battery while connected in-series

As batteries are connected in series, Instrumentation Amplifier is fed with input from Negative terminal and Positive terminal of Battery cell. At a time, first battery's negative terminal is going to first two Instrumentation amplifiers (say IA1 and IA2) simultaneously. Similar pattern is being followed in all the cases. Like second Battery's negative terminal will be going to next two Instrumentation amplifiers (say IA2 and IA3). This pattern will be followed by all consecutive battery cells. As each cell is giving its difference voltage across terminal to its dedicated Instrumentation amplifier, damage in any in between cell/s do not affect the operation of circuit measuring terminal voltage of battery cell.

\section{Conclusion and Future Scope}

This paper has proposed a scheme for State of charge estimation using dedicated Application specific Integrated circuit which is specifically designed for Battery Management Unit for Electric Vehicle. The proposed design embodied an Array of one-to-one high precision Instrumentation amplifier which utilizes to convert floating output into grounded output which can then forwarded via switching network which is controlled by demultiplexer whose select line are attached to GPIO of controller which stores data of individual voltage level of beach battery cell from battery pack. The feasibility of the balancing method has been verified by connecting 3 lithium-ion batteries in series in loading condition. The switching network is controlled by giving select inputs to demultiplexer which in turn operates switches one by one based on delay given from microcontroller. Result shows successfully voltage levels from individual battery cells, which are connected to dc motor (loading condition), can be retrieve even in loading condition.

\section{References}

[1]D. B. Karner, "Electric Transportation Applications, Glendale, "Current events in vehicle battery safety", in Proceedings of the 10th Annual Battery Conference on Application and Advances, pp. 167-169, January 1995.

[2]A. Affanni, A. Bellini, G. Franceschini, P. Guglielmi and C. Tassoni, "Battery choice and management for newgeneration electric vehicles," in IEEE Transactions on Industrial Electronics, vol. 52, no. 5, pp. 1343-1349, Oct. 2005.

[3]ieXu, Mingyu Gao, Zhiwei He, Jianbin Yao, Hongfeng Xu, "Design and Study on the State of Charge Estimation for Lithium-ion Battery Pack in Electric Vehicle", Artificial Intelligence and Computational Intelligence 2009. AICI '09. International Conference on, vol. 3, pp. 316-320, 2009.

[4]S. Bing-yu, G. Song, L. Hua, and W. Xin, "Research on high voltage fault diagnostics and safety management strategy of pure electric vehicle," Journal of Chongqing Jiaotong University, vol. 29, no. 5, pp. 804-807, 2010.

[5]J. Remmlinger, M. Buchholz, M. Meiler, P. Bernreuter, and K. Dietmayer, "State-of-health monitoring of lithium-ion batteries in electric vehicles by on-board internal resistance estimation," Journal of Power Sources, vol. 196, no. 12, pp. 5325-5331, 2011.

[6]C.-L. Lin, C.-T. Huang, W.-C. Lin, "Efficient energy managing control for electrical scooters", IET Electrical Systems in Transportation, vol. 2, pp. 9, 2012.

[7]Lei Pei, Rengui Lu, Chunbo Zhu, "Relaxation model of the open-circuit voltage for state-of-charge estimation in lithium-ion batteries", Electrical Systems in Transportation IET, vol. 3, no. 4, pp. 112-117, 2013.

[8]Ron Adany, Doron Aurbach, Sarit Kraus, "Switching algorithms for extending battery life in Electric Vehicles", Journal of Power Sources, vol. 231, pp. 50, 2013.

[9]Wangxin Huang, Jaber A. Abu Qahouq, "Distributed battery energy storage system architecture with energy sharing control for charge balancing", Applied Power Electronics Conference and Exposition (APEC) 2014 Twenty-Ninth Annual IEEE, pp. 1126-1130, 2014.

[10]M.M. Hoque, M.A. Hannan, A. Mohamed, A. Ayob, "Battery charge equalization controller in electric vehicle applications: A review", Renewable and Sustainable Energy Reviews, 2016. 
[11]Nisai H. Fuengwarodsakul, "Battery management system with active inrush current control for Li-ion battery in light electric vehicles", Electrical Engineering, vol. 98, pp. 17, 2016.

[12]Li Zhao, Muyi Lin, Yong Chen, "Least-squares based coulomb counting method and its application for state-of-charge (SOC) estimation in electric vehicles", International Journal of Energy Research, 2016.

[13]M. M. Hoque, M. A. Hannan, A. Mohamed, "Charging and discharging model of lithium-ion battery for charge equalization control using particle swarm optimization algorithm"Journal of Renewable and Sustainable Energy, Volume 8, Issue 6, 2016.

[14]Fengxian He, W.X. Shen, A. Kapoor, Damon Honnery, Daya Dayawansa, "H infinity observer based state of charge estimation for battery packs in electric vehicles", 2016 IEEE 11th Conference on Industrial Electronics and Applications (ICIEA).

[15]Yi-Hsun Hsieh, Tsorng-Juu Liang, Shih-Ming (Orion) Chen, Wan-Yi Horng, and Yi-Yuan Chung, "A Novel HighEfficiency Compact-Size Low-Cost Balancing Method for Series-Connected Battery Applications", IEEE TRANSACTIONS ON POWER ELECTRONICS, VOL. 28, NO. 12, DECEMBER 2013.

[16] Yang Du, and Dylan Dah-Chuan Lu," Analysis of a Battery-Integrated Boost Converter for Module-Based Series Connected Photovoltaic System", The 2010 International Power Electronics Conference. 